\title{
Specimen size effect on the residual properties of engineered cementitious composites subjected to high temperatures
}

\author{
Tahir Kemal Erdem* \\ Department of Civil Engineering, Izmir Institute of Technology, Izmir, Turkey
}

\section{A R T I C L E I N F O}

\section{Article history:}

Received 9 August 2012

Received in revised form 22 July 2013

Accepted 22 September 2013

Available online 29 September 2013

\section{Keywords:}

Engineered Cementitious Composites (ECC)

Specimen size effect

High temperature resistance

Mechanical properties

Pore size distribution

\begin{abstract}
A B S T R A C T
In this study, size effect on the residual properties of Engineered Cementitious Composites (ECC) was investigated on the specimens exposed to high temperatures up to $800{ }^{\circ} \mathrm{C}$. Cylindrical specimens having different sizes were produced with a standard ECC mixture. Changes in pore structure, residual compressive strength and stress-strain curves due to high temperatures were determined after air cooling. Experimental results indicate that despite the increase of specimen size, no explosive spalling occurred in any of the specimens during the high temperature exposure. Increasing the specimen size and exposure temperature decreased the compressive strength and stiffness. Percent reduction in compressive strength and stiffness due to high temperature was similar for all specimen sizes.
\end{abstract}

(C) 2013 Elsevier Ltd. All rights reserved.

\section{Introduction}

Engineered Cementitious Composite (ECC) is a newly developed, high-performance fiber-reinforced cementitious composite with substantial benefits; it offers high ductility under uniaxial tensile loading and improved durability due to an intrinsically tight crack width of less than $100 \mu \mathrm{m}[1,2]$. During the last decade the use of ECC has considerably grown up, and it was used in a variety of structures such as high-rise buildings, bridges, tunnels, highways, and other forms of infrastructures in North America, Europe and Asia, $[3,4]$. Significant attention has been brought to the study of its rheological, mechanical and durability related properties of ECC. The behavior of ECC exposed to high temperature has in particular to be evaluated. When a cement based composite is exposed to high temperature, it causes a material degradation in the form of strength decrease, cracking, and in some cases, spalling [5]. Mechanical properties and microstructure of fire-damaged ECC on $50 \mathrm{~mm}$ cubic specimens were assessed by Sahmaran et al. [6], and in that study it was concluded that the mechanical performance of fire-deteriorated ECC mixture is similar to or better than that of conventional concrete incorporating polypropylene or steel fibers. Although there was a significant reduction in compressive strength and stiffness, no explosive spalling was observed in any cubic ECC specimens during the fire test. The promising performance of ECC under fire exposure may be attributed to the presence of PVA fibers and high-volume fly ash (FA) [6]. In their

\footnotetext{
* Tel.: +90 232750 6813; fax: +90 2327506801 .

E-mail address: tahirkemalerdem@iyte.edu.tr
}

further research [7], they tried to understand the role of synthetic PVA fiber and different replacement levels of fly ash (FA) on the microstructural damage and residual mechanical properties of ECC after exposed to high temperatures. They concluded that incorporating PVA fiber seems to be a promising way to enhance the resistance of matrix to thermally induced explosive spalling, and increasing FA content from $55 \%$ to about $70 \%$ provides ECC with better residual mechanical properties after exposure to temperatures from 200 to $600{ }^{\circ} \mathrm{C}$.

As it is well known, the strength of brittle and defect-sensitive materials such as concrete depends to a significant extent upon the volume of the tested specimen [8]. This phenomenon is commonly referred to as "size effect" and reflects the fact that the probability of finding a crack of critical size and orientation increases with the number of cracks, i.e. with the volume of the specimen $[9,10]$. A review of the literature also showed that the risk of explosive thermal spalling increases with the increase in specimen size. This is due to the fact that specimen size has a direct effect on the rate of heat and moisture loss and the moisture content at the time of testing [11,12]. For example, a smaller size specimen provides a shorter path for moisture to escape during the fire test, thereby reducing spalling forces Therefore, careful consideration must be given to the size of specimens when evaluating the high temperature resistance and spalling behavior of cement-based composites.

As discussed above, although the residual properties of ECC after exposure to high temperatures have been studied comprehensively, the influence of specimen size on the residual properties, cracking and spalling of ECC has not been studied. The research described in this paper aimed to gain a better 
understanding of the influence of the specimen size on the behavior of ECC specimens exposed to elevated temperatures. For this purpose, standard ECC mixture, known also as ECC M45 and has a fly ash-cement ratio of 1.2 , by weight, was used. In order to find out the effect of specimen size on the behavior and residual properties of ECC mixtures exposed to high temperatures (up to $800^{\circ} \mathrm{C}$ ), ECC specimens having dimensions of $\varnothing 50 \times 100 \mathrm{~mm}$, $\varnothing 100 \times 200 \mathrm{~mm}$ and $\varnothing 150 \times 300 \mathrm{~mm}$ were tested. Microstructure, spalling, residual compressive strength and stress-strain curves of fire deteriorated ECC specimens were examined.

\section{Research significance}

The effects of high temperatures on the residual mechanical and microstructural properties of ECC had been widely researched. However, to the best of the author's knowledge, there is no investigation on the effect of specimen size on ECC behavior at high temperatures. A greater understanding of its fire performance will improve confidence in its use in civil engineering projects. This research adds important contribution to existing information on the behavior of ECC under elevated temperatures.

\section{Experimental studies}

\subsection{Materials, mix proportions and basic mechanical properties}

Standard ECC mixture (M45) with a fly ash-cement ratio (FA/C) of 1.2 by mass was used in this investigation, details of which are given in Table 1 . The materials used in the production of standard ECC mixture were Type I Portland cement (C), Class F fly ash (FA), sand, water, polyvinyl alcohol (PVA) fibers, and a polycarboxylicether type high-range water-reducing admixture (HRWR). Chemical composition and physical properties of cement and FA are presented in Table 2. Unlike typical fiber-reinforced cementitious composites, the component characteristics and proportions within the ECC are carefully determined with the use of micromechanical design tools to achieve the desired strain-hardening response [13]. To minimize the mortar matrix fracture toughness, no large aggregates were used, and the silica sand had an average grain size of $110 \mu \mathrm{m}$ and a maximum size of $200 \mu \mathrm{m}$. The PVA fibers with a diameter of $39 \mu \mathrm{m}$ and a length of $8 \mathrm{~mm}$ are purposely manufactured with a tensile strength $(1620 \mathrm{MPa})$, elastic modulus

Table 1

Mixture properties of ECC.

\begin{tabular}{lc}
\hline & ECC \\
\hline Cement $(\mathrm{C})\left(\mathrm{kg} / \mathrm{m}^{3}\right)$ & 558 \\
Fly ash $(\mathrm{FA})\left(\mathrm{kg} / \mathrm{m}^{3}\right)$ & 669 \\
Water $(\mathrm{W})\left(\mathrm{kg} / \mathrm{m}^{3}\right)$ & 326 \\
PVA fiber $\left(\mathrm{kg} / \mathrm{m}^{3}\right)$ & 26 \\
Sand $\left(\mathrm{kg} / \mathrm{m}^{3}\right)$ & 446 \\
HRWR $\left(\mathrm{kg} / \mathrm{m}^{3}\right)$ & 2.3 \\
W/(C+FA) & 0.27 \\
FA/C & 1.2 \\
28-Day tensile strain $(\%)$ & 2.7 \\
28-Day tensile strength $(\mathrm{MPa})$ & 5.1 \\
\hline
\end{tabular}

(42.8 GPa), and maximum elongation (6.0\%) matching those needed for strain-hardening performance. Additionally, the surface of the PVA fibers is coated with a proprietary oiling agent $1.2 \%$ by mass to tailor the interfacial properties between fiber and matrix for strain-hardening performance [13].

ECC mixture was prepared in a standard mortar mixer at water to cementitious material ratio of 0.27 . HRWR was added to the mixture until the desired fresh ECC characteristics were visually observed [14]. To characterize the direct tensile behavior of the ECC mixtures, $152 \times 76 \times 13 \mathrm{~mm}$ coupon specimens were used. Direct tensile tests were conducted under displacement control at a loading rate of $0.005 \mathrm{~mm} / \mathrm{s}$. The typical tensile stress-strain curves of ECC mixtures at 28 days are shown in Fig. 1. As seen from the figure, after first cracking, the uniaxial tensile stress increased at a slower rate, along with the development of multiple cracks with small crack spacing and tight crack widths. The ultimate tensile strain and uniaxial tensile strength capacity of ECC mixture at 28 days are listed in Table 1 . As seen in Table 1, the ECC composite exhibited a strain capacity of $2.7 \%$ at 28 days. After direct tensile testing, all residual crack widths were also measured in the unloaded stage on the surface of the specimens using a portable microscope. All of the ECC coupon specimens showed multiple cracking behavior with small crack spacing and tight crack widths $(<70 \mu \mathrm{m})$.

\subsection{Test specimen preparation and testing}

To investigate the influence of size effect on pore structure, residual compressive strength and stress-strain curve of ECC, several cylindrical specimens having a constant length-to-diameter ratio of two and dimensions of $\varnothing 50 \times 100 \mathrm{~mm}, \varnothing 100 \times 200 \mathrm{~mm}$ and $\varnothing 150 \times 300 \mathrm{~mm}$ were cast. The choice of maximum cylindrical specimen size $(\varnothing 150 \times 300 \mathrm{~mm}$ for this study) was limited by the size of the furnace to be used in the heating process. Specimens were removed from the molds at 1 day, and kept in a climatic chamber until the age of 28 days at $23 \pm 2{ }^{\circ} \mathrm{C}$ and $95 \pm 5 \% \mathrm{RH}$. At 28 days, six specimens from each size were tested under compression immediately after conditioning; these control specimens will be referred to as those tested after exposure to normal curing condition (unheated). Before testing, both ends of the cylindrical

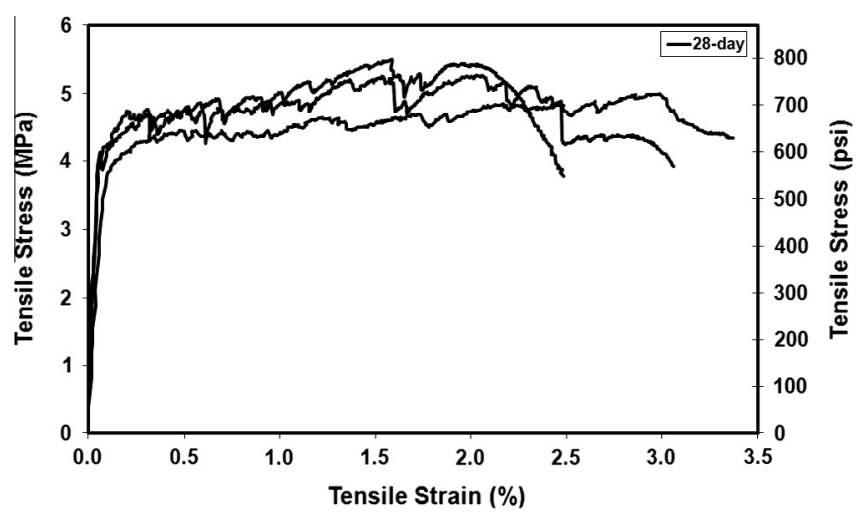

Fig. 1. Typical tensile stress-strain response of standard ECC mixture (M45).

Table 2

Chemical composition and physical properties of cement and fly ash.

\begin{tabular}{|c|c|c|c|c|c|c|c|c|c|c|c|c|}
\hline & \multicolumn{9}{|c|}{ Chemical composition (\%) } & \multicolumn{3}{|c|}{ Physical properties } \\
\hline & $\mathrm{CaO}$ & $\mathrm{SiO}_{2}$ & $\mathrm{Al}_{2} \mathrm{O}_{3}$ & $\mathrm{Fe}_{2} \mathrm{O}_{3}$ & $\mathrm{MgO}$ & $\mathrm{SO}_{3}$ & $\mathrm{~K}_{2} \mathrm{O}$ & $\mathrm{Na}_{2} \mathrm{O}$ & LOI & Spec. grav. & Ret. on $45 \mu \mathrm{m}(\%)$ & Water req. (\%) \\
\hline Cement & 61.8 & 19.4 & 5.3 & 2.3 & 0.9 & 3.8 & 1.1 & 0.2 & 2.1 & 3.15 & 12.9 & - \\
\hline Fly ash & 5.6 & 59.5 & 22.2 & 3.9 & - & 0.2 & 1.1 & 2.7 & 0.2 & 2.18 & 9.6 & 93.4 \\
\hline
\end{tabular}


specimens were capped with sulfur in accordance with ASTM C617. At the same age, the remaining specimens were exposed to predefined temperature levels for an hour, and after air cooling, their residual properties (compressive strength, stress-strain curves and pore-size distribution) were investigated according to the following procedure: Computer controlled furnace was used for the heating of specimens with constant heating rate of about $15^{\circ} \mathrm{C} / \mathrm{min}$ to reach the prescribed $200,400,600$, and $800^{\circ} \mathrm{C}$ temperature levels. The temperature was measured in the air at a position above the specimen inside the furnace. When the heat of the kiln was reached to target peak temperature, the kiln temperature was maintained constant for an hour to achieve the thermal steady state condition. It was expected that because of small size of specimens used in this study, the temperature in the center of the specimen reached the target temperature during the one hour stabilization phase. This heating regime, ECC mixture proportion and ingredients were identical to that previously reported for investigating the residual mechanical properties of ECC [6,7]. After heating, the samples were allowed to cool down naturally to the room temperature. After cooling, both ends of those specimens were also capped and the compressive strength tests were carried out on them. An axial load test was performed under displacement control at a loading rate of $0.005 \mathrm{~mm} / \mathrm{s}$ on a closed-loop controlled material testing system with $200 \mathrm{kN}$ capacity. During the compressive tests, the load and the deflection values (obtained from a pair of LVDT's attached to the test set-up) were recorded on a computerized data acquisition system. At least four samples were tested for each temperature and specimen size, and mean values were calculated.

To obtain an insight into the residual properties, the pore size distribution was determined by the mercury intrusion porosimetry (MIP) technique. Pore structure data from MIP allow quantification of the changes in the structure and understanding the mechanisms of ECC deterioration due to external effects such as elevated temperatures. Pore structure of unheated and heated specimens was determined on the mid-center of $\varnothing 150 \times 300 \mathrm{~mm}$ cylindrical specimens by the Pascal 240 type MIP test device. An instrument capable of producing pressures up to $414 \mathrm{MPa}$ and assuming a contact angle of $130^{\circ}$ was used for pore size distribution analysis. Prior to testing, specimens were dried to a constant weight at $50{ }^{\circ} \mathrm{C}$. In all cases, at least two identical ECC specimens were tested at the same time, and mean values were calculated. MIP test results of the current study were compared with MIP results of a previous study, which employed $50 \mathrm{~mm}$ cubic specimens [6]. By this way, the variations as a result of size effect were defined.

\section{Results and discussions}

\subsection{Pore structure characterization of heat treated ECC specimens}

For cement based composites subjected to high temperature, an increase in temperature causes a decrease in mechanical properties degenerates internal structure and develops microdefects. Therefore, studying the pore structure of cement based composites after high-temperature exposure helps to understand the

Table 3

Total intruded porosity variation of ECC specimens.

\begin{tabular}{lll}
\hline Specimen type & Total intruded porosity $(\%)$ \\
\cline { 2 - 3 } & $\varnothing 150 \times 300 \mathrm{~mm}$ cylinder & $50 \mathrm{~mm}$ cube \\
\hline Control (unheated) & 24.7 & 23.7 \\
$200{ }^{\circ} \mathrm{C}$ & 26.5 & 23.9 \\
$400{ }^{\circ} \mathrm{C}$ & 27.4 & 28.6 \\
$600{ }^{\circ} \mathrm{C}$ & 34.8 & 32.0 \\
$800^{\circ} \mathrm{C}$ & 44.5 & 32.4 \\
\hline
\end{tabular}

mechanisms of deterioration [15,16]. MIP is a well-developed technique that can provide information about pore structure, including the porosity, average pore diameter, and pore size distribution of ECC [6]. In this study, since similar tendency for the change in mechanical properties with temperature were monitored for the studied specimen sizes (as will be discussed in the next section), MIP measurements were only performed on $\varnothing 150 \times 300 \mathrm{~mm}$ cylindrical specimens by obtaining fragments from their core. The deterioration of ECC's structural integrity, when exposed to various temperatures, is illustrated by total intruded porosity increase in Table 3. As seen in the table, when the exposure temperature increased, total intruded porosity of the ECC specimens also increased. The total intruded porosity of the ECC specimens increased about 7.3\%, 10.9\%, 40.9\% and $80.2 \%$ with respect to the total intruded porosity of control specimens (unheated) for the exposure temperatures of 200, 400, 600 and $800{ }^{\circ} \mathrm{C}$, respectively. In terms of total intruded porosity, changes appeared more rapidly with temperatures over $600^{\circ} \mathrm{C}$, which is in agreement with the data reported in the literature [6,7]. For the comparison purpose, total intruded porosity values of $50 \mathrm{~mm}$ cubic specimens [6], was also given in Table 3. As seen in the table, the total intrusion porosity values of current (measured from the specimens obtained from the core of $\varnothing 150 \times 300 \mathrm{~mm}$ cylinder specimens) and reference study (measured from the specimens obtained from the core of $50 \mathrm{~mm}$ cubic specimens) was almost same up to $600^{\circ} \mathrm{C}$. At exposure temperatures of $800^{\circ} \mathrm{C}$, the average total intruded porosity value of $\varnothing 150 \times 300 \mathrm{~mm}$ cylinder specimens is $38 \%$ higher than that of $50 \mathrm{~mm}$ cubic specimen. The relationship of $\mathrm{d} V / \mathrm{d} \log D$ versus $\log D$ (see Fig. 2) has also been used to reflect the pore size distribution, in which $V$ is mercury intrusion volume and $D$ is pore diameter. Mechanical properties of a material are strongly related to its microstructure. Therefore, to a certain degree, the variation of pore structure reflects the deterioration of concrete subjected to high temperature [17]. The results given in Fig. 2, confirm the coarsening effect of high temperatures on the
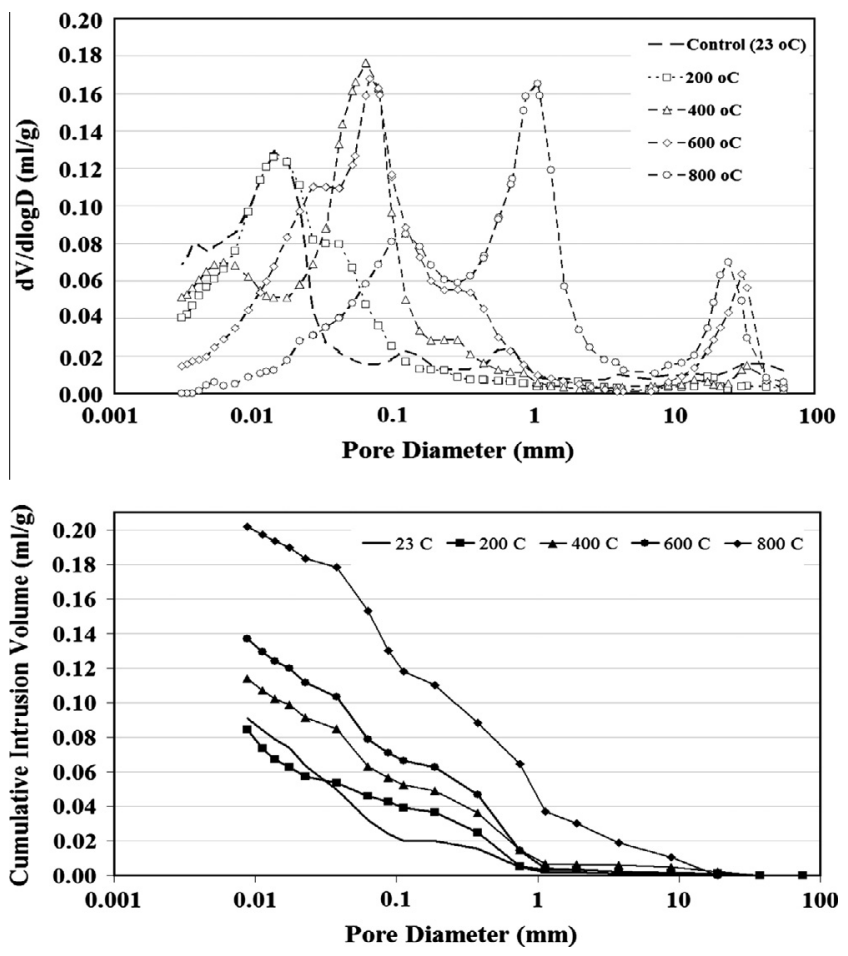

Fig. 2. Pore size distributions and cumulative intrusion volume before and after exposure to high temperature. 
pore structure reported previously [16-18]. Fig. 2 also indicates that the total intruded volume of mercury per gram of the sample increases with the increase of exposure temperature.

Fig. 3 indicates the volumes of intruded mercury in a predefined range of pores, which were normalized with the total volume of intruded mercury for each exposure temperature. Wu et al. [19] and Mehta [20] divided the pore structure into four groups, namely, gel pore $(<10 \mathrm{~nm})$, transitional pore $(10-50 \mathrm{~nm})$, capillary pore $(50-100 \mathrm{~nm})$ and macropore (>100 nm). In current research, 7.5$50 \mathrm{~nm}, 50-125 \mathrm{~nm}, 125-500 \mathrm{~nm}$ and $500-100,000 \mathrm{~nm}$ are defined as the range of pore volumes, and the distribution of volume of pores in those ranges were calculated. As seen in figure, percent of pore volumes amended according to the exposed high temperature level. For instance, although the total volume of $7.5-50 \mathrm{~nm}$ and $50-125 \mathrm{~nm}$ (gel + transition + capillary) pores were $77.9 \%$ at control (unheated) specimens, the total of those volumes decreased gradually to $56.8 \%, 57.1 \%, 54.4 \%$ and $45.4 \%$ for the specimens exposed to $200,400,600$, and $800^{\circ} \mathrm{C}$, respectively. When the total volume of (gel + transition + capillary) pores decreased, volume of macropores (pores larger than $125 \mathrm{~nm}$ ) increased significantly and reached to $54.6 \%$ at $800{ }^{\circ} \mathrm{C}$. Moreover, as illustrated in Fig. 3, pore volume distribution of the specimens which were exposed to $200{ }^{\circ} \mathrm{C}, 400{ }^{\circ} \mathrm{C}$ and $600{ }^{\circ} \mathrm{C}$ were similar, and remarkable alteration took place after $600^{\circ} \mathrm{C}$. The significant and unique increase of pore volume of macropores for the ECC specimens exposed to $800{ }^{\circ} \mathrm{C}$ found in this study strongly suggests that pores of this size may be responsible for the significant deterioration in compressive strength, as discussed in next section. The degradation of hydrates (C-S-H gels), which is inevitable $[6,7,21]$ when the exposure temperature is raised to $600{ }^{\circ} \mathrm{C}$ and above, is the main reason for severe pore structure coarsening.

\subsection{Surface characteristics and spalling of heat treated ECC specimens}

Spalling is defined as damage where concrete surface scales and falls off from the concrete along with explosion at a high temperature [22]. The spalling of concrete under high temperatures is a concern due to exposure of the steel reinforcement to direct fire contact and subsequent structural capacity loss of the element [7]. It was mentioned in the literature that the possible reason behind explosive spalling might be the internal cracking, pore pressure, rapid heating of concrete specimens, moisture content and strength grade of concrete [23-25]. In this study, no explosive spalling was observed in ECC cylinder specimens even after exposure to $800{ }^{\circ} \mathrm{C}$. This situation is valid for all studied specimen sizes. Normally, it is expected that the risk of explosive spalling must be

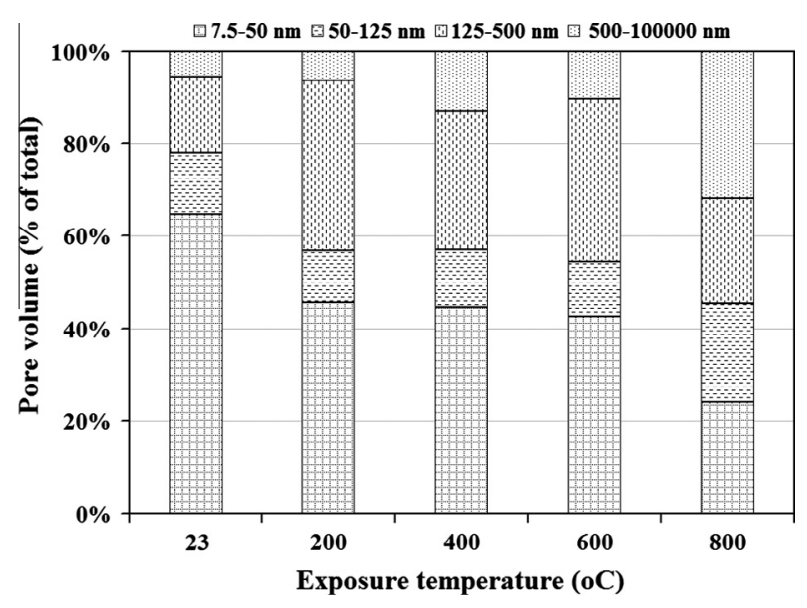

Fig. 3. Percent volume variation of pore size. increased with the increase of specimen size due to the heat and moisture transport through the specimen $[11,12,23]$. The microstructure of the tested specimen controls the water expulsion from the concrete at normal as well as at high temperature. Therefore, the pore structure at high temperature exposure may have a considerable influence on the spalling behavior of ECC. In this research, although the choice of specimen size was limited by the size of the kiln, the increase in specimen size did not significantly alter the total intruded porosity and pore size diameter up to $600{ }^{\circ} \mathrm{C}$ compared to the MIP measurements on $50 \mathrm{~mm}$ cubic specimen, as demonstrated in the pore structure section. After that temperature level, total porosity and pore diameters get remarkably coarser while no explosive spalling was also monitored. For normal and high strength concretes without fibers, not all water is expelled fast enough from the concrete specimen when exposed to high temperatures. As specimen gets larger, the becoming distant time of water increases. This will result in vaporization at higher temperatures and the creation of high pressures inside the tested specimen. However, for ECC, as a result of PVA fiber which is melted under temperatures slightly above $200{ }^{\circ} \mathrm{C}$, additional porosity and small channels are created by the melting of PVA fiber. This may lower internal vapor pressures in the ECC, and newly formed inter-connected pores inside the ECC specimens might give permission to escape of moisture, resulting in the elimination of the occurrence of explosive spalling due to the vapor pressures. As seen in Fig. 4, the PVA fiber content used in ECC ( $2 \%$, by volume) is high enough so that fibers alone constitute a connected network. Therefore, the use of PVA fiber clearly affects porosity at temperatures above $200{ }^{\circ} \mathrm{C}$.

Surface crack patterns of the all studied ECC specimen sizes due to the high temperature exposure were almost same up to $600^{\circ} \mathrm{C}$. Cracks became apparent after $400^{\circ} \mathrm{C}$, and hairline cracks were monitored above $400{ }^{\circ} \mathrm{C}$. No physical difference was also observed on the surface of the specimen due to the specimens' size variation. Increasing the exposure temperature to $600{ }^{\circ} \mathrm{C}$ increased the size of microcracking as consistent with pore structure variation of the specimens. However, the visual inspection of the surface crack pattern of ECC specimens exposed to $800^{\circ} \mathrm{C}$ showed that crack size varied with specimen size: as the specimen size increased, the size of surface crack got coarser as demonstrated in Fig. 5.

\subsection{Residual compressive strength and stress-strain curves}

The results of compressive strength tests are given in Fig. 6. Each point in Fig. 6 was obtained from the average of four to six companion test specimens. The coefficient of variance (COV) values

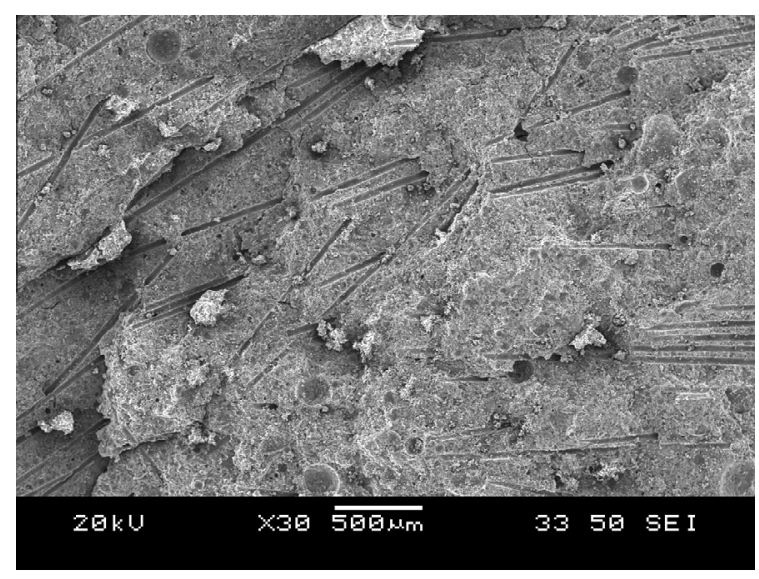

Fig. 4. SEM micrograph of ECC specimen $(\varnothing 150 \times 300 \mathrm{~mm})$ after exposure to $400{ }^{\circ} \mathrm{C}$. 

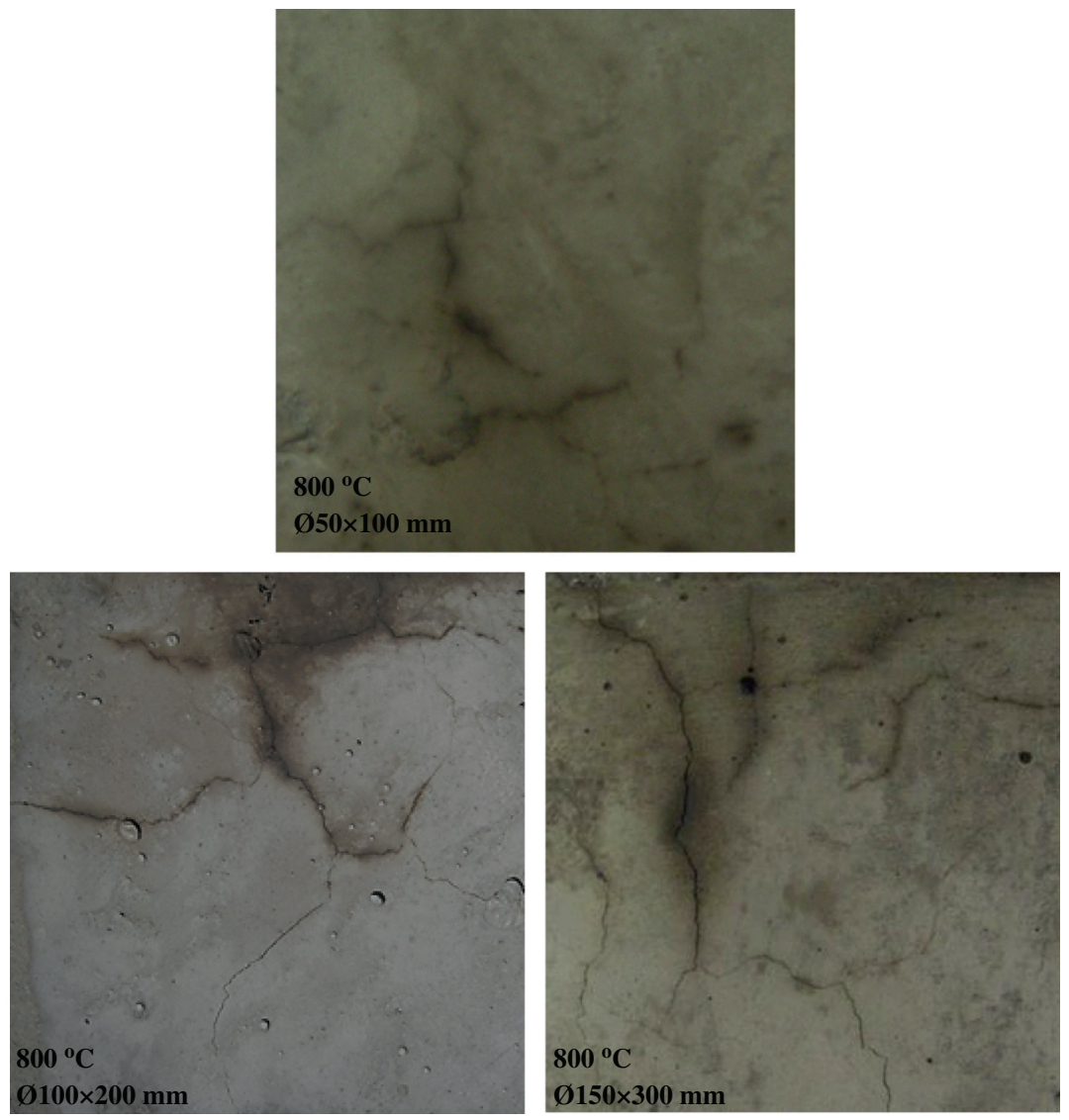

Fig. 5. Surface cracking pattern of ECC specimens exposed to $800^{\circ} \mathrm{C}$.

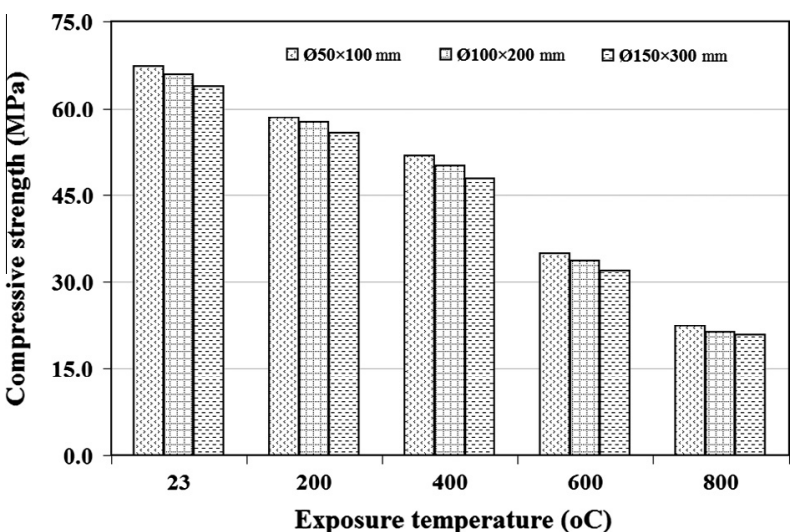

Fig. 6. Compressive strength variation of ECC after high temperature exposures.

for the compressive strength values ranged from $7.3 \%$ to $13.1 \%$. The narrow range of COV values is an indication of the consistent repeatability of the compressive strength test method even for fire-deteriorated specimens. In accordance with specimen size, the average compressive strength of unheated ECC specimens varies between 63.9 and 67.2 MPa. From Fig. 6 it can be seen that as the specimen dimensions increase, the strength of the specimen decreases. Reasons of this phenomenon can be expressed as by means of statistical approach; the number of microcracks and defects in smaller specimens are fewer than bigger specimens, resulting in a rise in density [26].

As seen in Fig. 6 and as expected, exposure to high temperature influenced the residual compressive strength of ECC specimens substantially, irrespective of the specimen size. Influence of the high temperature exposure on the residual compressive strength is not prominent up to $400{ }^{\circ} \mathrm{C}$ exposure temperature. For instance, mean compressive strength of the $\varnothing 100 \times 200 \mathrm{~mm}$ sized cylinder specimen decreased from 65.9 MPa to $50.2 \mathrm{MPa}$ (or 24\%) after exposure to $400{ }^{\circ} \mathrm{C}$. This might be due to the less sensitivity of compressive strength to minor microcracks. As discussed above, heating up to $400{ }^{\circ} \mathrm{C}$ generated a relatively small amount of cracking, which did not cause any immediate loss of carrying capacity in compression because the slightly cracked concrete could work as a highly redundant structure [27]. Beyond $400^{\circ} \mathrm{C}$, however, compressive strength dropped drastically from $65.9 \mathrm{MPa}$ to $33.7 \mathrm{MPa}$ and $21.3 \mathrm{MPa}$ at 600 and $800{ }^{\circ} \mathrm{C}$, respectively, corresponding to $50 \%$ and $70 \%$ reductions. According to the variation of the residual compressive strength, temperature of $600{ }^{\circ} \mathrm{C}$ and above might be

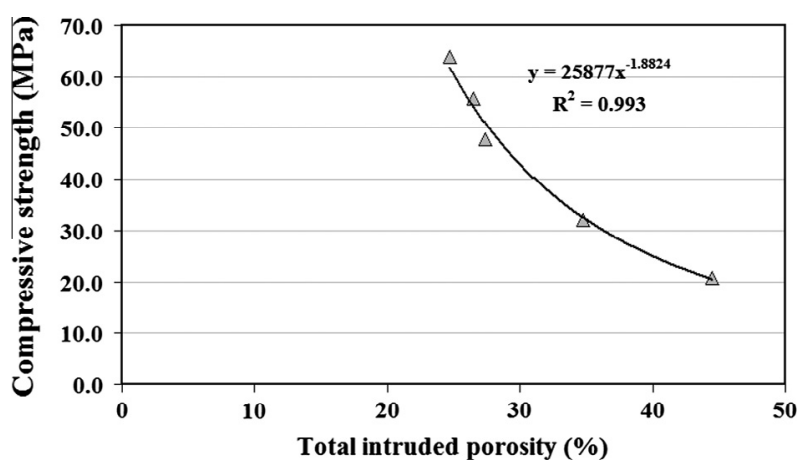

Fig. 7. Total intruded porosity and compressive strength relationship. 


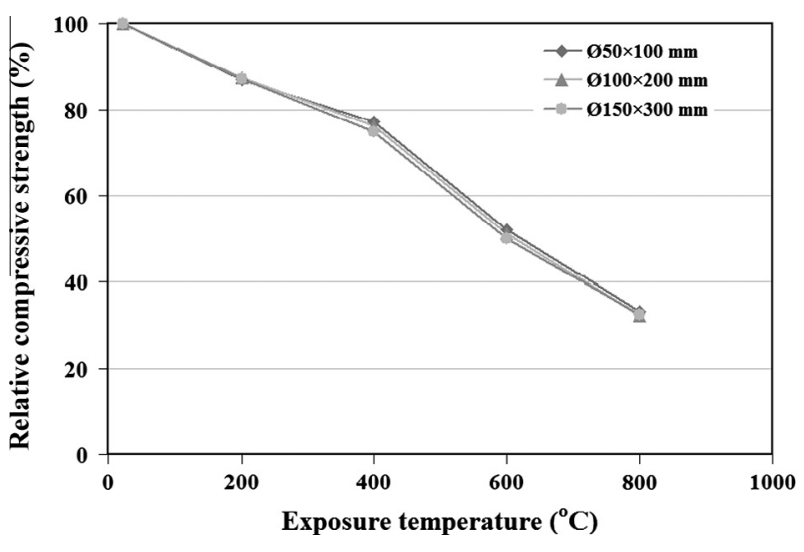

Fig. 8. Compressive strength degradation owing to high temperature exposure.

regarded as critical temperature range for the strength loss of ECC. The present test results are in line with the findings of previous studies [6,7]. Residual compressive strength variations are consis- tent with the pore structure variations (see Fig. 7). As seen in Fig. 3, the total intruded porosity and percent of pore size between $50 \mathrm{~nm}$ and $500 \mathrm{~nm}$ increased slightly with the increase of temperature up to $400{ }^{\circ} \mathrm{C}$. The increase in porosity up to $400{ }^{\circ} \mathrm{C}$ is most likely due to small channels created in ECC by melting PVA fibers (see Fig. 4). However, after exposure to $600{ }^{\circ} \mathrm{C}$, the main causes of deterioration in compressive strength might be attributed both to the physical transformation of the matrix and chemical transformation of hydration products. When the temperature was raised to $600^{\circ} \mathrm{C}$, decomposition of the major hydrate, known as tobermorite (gel), was inevitable [21], causing severe increase in the microstructure of its matrix and the loss of binder property [6,7]. Moreover, decomposition of fine silica sand at $800{ }^{\circ} \mathrm{C}$ was also demonstrated by scanning electron microscopy [7].

In order to visualize the extent of damage due to the exposed high temperatures on the residual compressive strength of ECC specimens with different sizes, percent change in the compressive strength is determined against the specimen size and exposure temperature. Fig. 8 shows the ratio of the average strength of ECC samples that were exposed to high temperature to that of the control (unheated) samples. As seen in the figure, percent
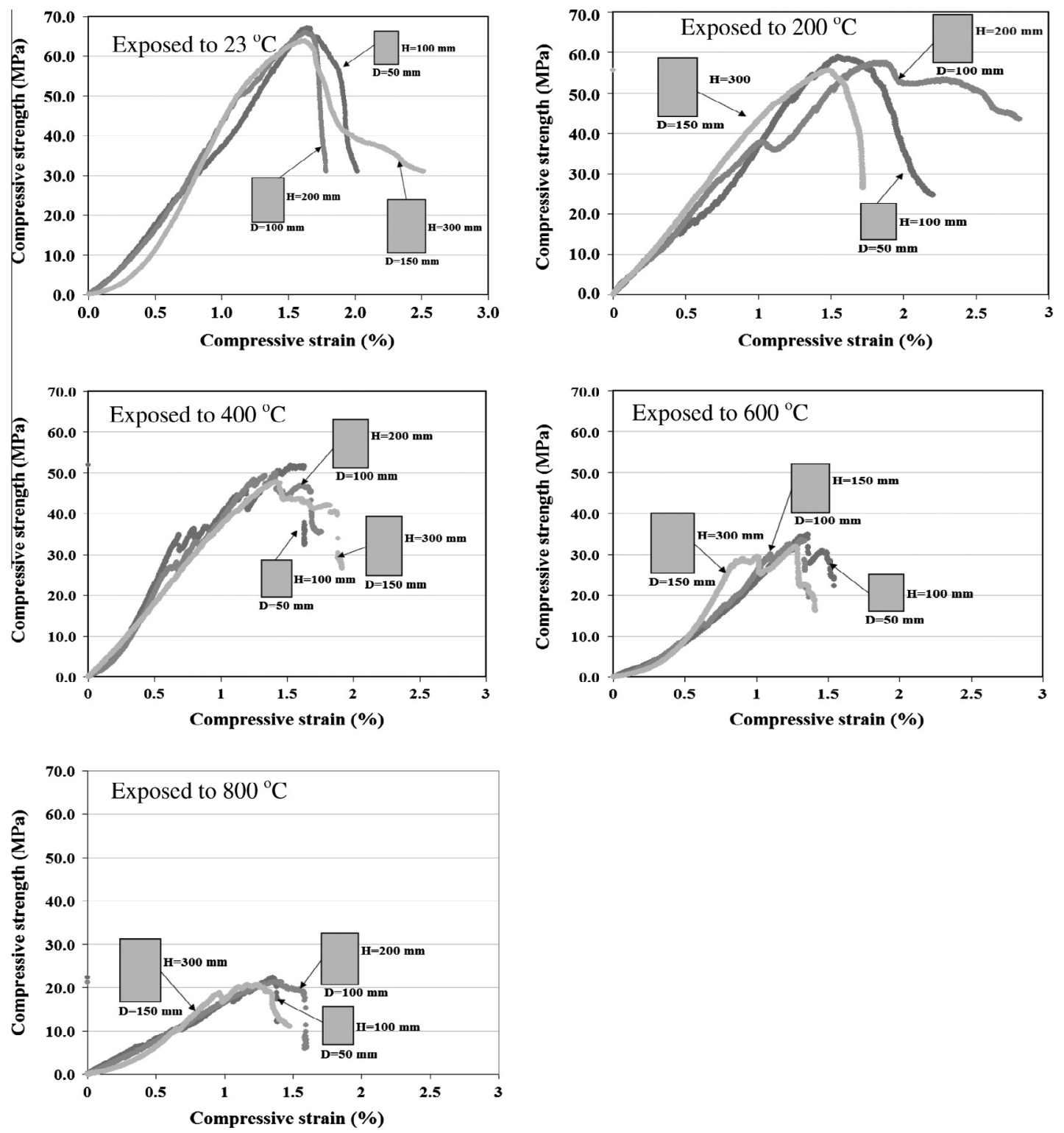

Fig. 9. Compressive strength-strain variations of ECC specimens. 
reduction in compressive strength can be classified in three distinct patterns of strength loss, $23-400{ }^{\circ} \mathrm{C}, 400-600^{\circ} \mathrm{C}$ and $600-800^{\circ} \mathrm{C}$. From 23 to $400{ }^{\circ} \mathrm{C}$, slope of relative strength versus exposure temperature is linear, and reduction in compressive strength was around $20 \%$ for all specimen dimensions. Between $400{ }^{\circ} \mathrm{C}$ and $600^{\circ} \mathrm{C}$, average loss in compressive strength is significantly higher compared to the range of $23-400{ }^{\circ} \mathrm{C}$ and reach to $50 \%$. Beyond $600{ }^{\circ} \mathrm{C}$, in the last range, ECC specimens showed severe deterioration, most probably, due to the decomposition of hydration gels $[21,28]$. The average residual strength was dropped to about 35\%, regardless of specimen size. As also evidently seen in Fig. 8, percent reduction in compressive strength is virtually same for all studied specimens size. Normally, as mentioned earlier, deterioration of the cement based composites are altering due to the fact that specimen size is directly related to the heat and moisture transport through the structure. The larger structures store more energy and as the specimen gets bigger, the deterioration and risk of thermal spalling gets higher. Therefore, within the range of specimen sizes studied, ECC can be accepted as the size effect independent of thermal exposure.

The stress-strain curves for different sized ECC specimens at room and elevated temperatures are compared in Fig. 9. In this figure, similar tendency for the change in compressive strength-strain curves with temperature was monitored for the studied specimen sizes. Strain corresponding to the peak strength did not significantly change with the variation of specimen size; a small amount of decrease in peak strain was observed with the increase of specimen size. As expected, with the increase of exposure temperature, the post peak stress of the ECC specimens dropped faster, resulting in a smaller post peak area under the curve. This behavior becomes more evident when the exposure temperature level reaches to $800{ }^{\circ} \mathrm{C}$ : ECC specimens failed soon after reaching their peak strength. This means that increasing the exposed temperature level tends the ductile nature of ECC to brittle nature.

As it is known, the slope of the load-deflection curve represents the stiffness of the specimens. As seen in Fig. 9, the slope decreases with the increase in exposure temperature up to $800^{\circ} \mathrm{C}$, indicating a reduction in the stiffness of the ECC. Reduction in ECC stiffness was relatively low up to $400{ }^{\circ} \mathrm{C}$, however, beyond that temperature level, a dramatic reduction was monitored in the ECC stiffness. The test results given in Fig. 9 clearly demonstrated that within the range of specimen sizes studied, as in the compressive strength test results, the stiffness values are not affected by specimen size after high temperature exposure.

\section{Conclusions}

The objective of the present work was to investigate the influence of the specimen size on the behavior of ECC specimens exposed to elevated temperatures. A standard ECC mixture (M45) with fly ash/portland cement ratio of 1.2 was investigated. To investigate the influence of specimen size effect on the residual compressive strength and stress-strain curve of ECC exposed to various temperatures up to $800^{\circ} \mathrm{C}$, cylindrical specimens having dimensions of $\varnothing 50 \times 100 \mathrm{~mm}, \varnothing 100 \times 200 \mathrm{~mm}$ and $\varnothing 150 \times 300 \mathrm{~mm}$ were cast. The results of mercury intrusion porosity analyses were combined in order to clarify the changes in the mechanical properties at high temperatures. Based on this study, the following conclusions can be drawn:

No significant change in compressive strength and stiffness for tested specimens exposed to temperature of $200^{\circ} \mathrm{C}$ were found. There was also no visible effect on the surface of the specimens at this temperature. For exposure to temperatures of $400^{\circ} \mathrm{C}$, a slight reduction $(\sim 15 \%)$ in compressive strength and stiffness, and slight increase in total intruded porosity and pore size diameter were observed in the tested specimens. Small hairline cracks were also observed on the surface after specimens had been exposed to $400{ }^{\circ} \mathrm{C}$. After exposure to $600{ }^{\circ} \mathrm{C}$, the ECC specimens retained about $50 \%$ of its compressive strength, and surface cracking was more significant. The compressive strength of ECC decreased even more when the exposure temperature was raised to $800^{\circ} \mathrm{C}$. After that temperature level, total porosity and pore diameters got remarkably coarser, however, no explosive spalling was monitored in any of the specimens tested.

Although the choice of maximum specimen size was limited by the size of the furnace, compared to the MIP measurements on $50 \mathrm{~mm}$ cubic specimen [6], the increase of specimen size did not significantly alter the total intruded porosity. Moreover, within the size of the specimens studied, the specimen size did not play an important role on the residual mechanical properties of ECC when the specimens were heated up to $800^{\circ} \mathrm{C}$. The stress-strain curve of different sized specimens was also found to be almost similar for all exposure temperatures. Therefore, from the high temperature deterioration point of view, ECC can be accepted as the specimen size effect independent.

Results of the fire test on the ECC specimens with different specimen dimensions are somewhat conclusive; however, in order to increase confidence in predicting the behavior of ECC structural members under fire exposure, fire tests on full-scale structural members will need to be carried out.

\section{References}

[1] Li VC. ECC-Tailored composites through micromechanical modeling. In: Banthia N, editor. Proceeding fiber reinforced concrete: present and the future conference. Montreal: CSCE Press; 1998. p. 64-97.

[2] Li VC. On engineered cementitious composites (ECC) - A review of the material and its applications. J Adv Concr Technol 2003;1(3):215-30.

[3] Kunieda M, Rokugo K. Recent progress on HPFRCC in Japan. J Adv Concr Technol 2006;4(1):19-33.

[4] Li VC, Lepech M, Li M. Field demonstration of durable link slabs for jointless bridge decks based on strain-hardening cementitious composites. Report for Michigan Department of Transportation (DOT) RC-1438; 2005.

[5] Fares H, Remond S, Noumowe A, Cousture A. High temperature behaviour of self-consolidating concrete Microstructure and physicochemical properties. Cem Concr Res 2010;40:488-96.

[6] Sahmaran M, Lachemi M, Li VC. Assessing mechanical properties and microstructure of fire-damaged engineered cementitious composites. ACI Mater J 2010;107(3):297-304.

[7] Sahmaran M, Özbay E, Yücel HE, Lachemi MLVC. Effect of fly ash and PVA fiber on microstructural damage and residual properties of engineered cementitious composites exposed to high temperatures. ASCE J Mater Civ Eng 2011;23(12):1735-45.

[8] Tanigawa Y, Yamada K. Size effect in compressive strength of concrete. Cem Concr Res 1978;8:81-90.

[9] (a) Neville AM. Some aspects of the strength of concrete. London. Civil Engineering and Public Works Review Part I: V 1959;54(639):1153-6; (b) Neville AM. Some aspects of the strength of concrete. London. Civil Engineering and Public Works Review Part I: V 1959;54(641):1435-9; (c) Neville AM. Some aspects of the strength of concrete. London. Civil Engineering and Public Works Review Part I: V 1959;54(640):1308-10.

[10] Fanella D, Krajcinovic D. Size effect in concrete. J Eng Mech 1988;114(4):704-15.

[11] Sanjayan G, Stocks LJ. Spalling of high-strength silica fume concrete in fire. ACI Mater J 1993;90(2):70-173.

[12] Biolzi L, Cattaneo S, Rosati G. Evaluating residual properties of thermally damaged concrete. Cem Concr Compos 2008;30:907-16.

[13] Li VC, Wu C, Wang S, Ogawa A, Saito T. Interface tailoring for strain-hardening PVA-ECC. ACI Mater J 2002;99(5):463-72.

[14] Yang EH, Sahmaran M, Yang Y, Li VC. Rheological control in the production of engineered cementitious composites. ACI Mater J 2009;106(4):357-66.

[15] Zhang B. Relationship between pore structure and mechanical properties of ordinary concrete under bending fatigue. Cem Concr Res 1998;28:699-711.

[16] Rostasy SF, Weiß R, Wiedemann G. Changes of pore structure of cement mortars due to temperature. Cem Concr Res 1980;10:157-64.

[17] Chan YN, Luo X, Sun W. Compressive strength and pore structure of highperformance concrete after exposure to high temperature up to $800{ }^{\circ} \mathrm{C}$. Cem Concr Res 2000;30:247-51.

[18] Ghan YN, Peng GF, Anson M. Residual strength and pore structure of highstrength concrete and normal strength concrete after exposure to high temperatures. Cem Concr Compos 1999;21:23-7. 
[19] Wu Z, Huizhen L. High performance concrete. Beijing: China Railway Publishing House; 2000.

[20] Mehta PK. Concrete in the marine environment (modern concrete technology series). New York: Taylor\& Francis Group; 2003.

[21] Khoury GA, Grainger BN, Sullivan PJE. Transient thermal strain of concrete: literature review, conditions within specimen and behavior of individual constituents. Mag Concr Res 1985;37(132):131-44.

[22] Han CG, Hwang YS, Yang SH, Gowripalan N. Performance of spalling resistance of high performance concrete with polypropylene fiber contents and lateral confinement. Cem Concr Res 2005;35:1747-53.

[23] Peng GF, Yang WW, Zhao J, Liu YF, Bian SH, Zhao LH. Explosive spalling and residual mechanical properties of fiber-toughened high-performance concrete subjected to high temperatures. Cem Concr Res 2006;36:723-7.
[24] Dougill JW. Modes of failure of concrete panels exposed to high temperatures. Mag Concr Res 1972;24:71-6.

[25] Chan YNS, Peng GF, Anson M. Fire behavior of high performance concrete made with silica fume at different moisture contents. ACI Mater 1999;95:405-9.

[26] Aïtcin PC, Miao B, Cook WD, Mitchell D. Effects of size and curing on cylinder compressive strength of normal and high strength concretes. ACI Mater 1994;91(4):349-54.

[27] Hsu TTC, Slate FO, Sturman GM, Winter G. Microcracking of plain concrete and the shape of the stress-strain curve. ACI Mater J 1963;60(2):209-24.

[28] Lin WM, Lin TD, Powers-Couche LJ. Microstructures of fire-damaged concrete. ACI Mater J 1996;93(3):199-205. 